\title{
Garantismo Penal para Quem? O Discurso Penal Liberal Frente à sua Desconstrução pela Criminologia
}

\author{
Criminal Guarantees for Whom? The Speech Liberal Criminal Front to this \\ Deconstruction by Criminology
}

\author{
Marisa Helena D'Arbo Alves de Freitas \\ Universidade Estadual Paulista Júlio de Mesquita Filho, Franca - SP, Brasil \\ Renan Posella Mandarino \\ Universidade Estadual Paulista Júlio de Mesquita Filho, Franca - SP, Brasil \\ Larissa Rosa \\ Universidade Estadual Paulista Júlio de Mesquita Filho, Franca - SP, Brasil
}

\begin{abstract}
Resumo: O presente artigo versa sobre a efetividade das garantias individuais e o reflexo dessa problemática no acesso à justiça penal brasileira. Apesar de o discurso garantista apresentar os instrumentos possíveis para defesa dos acusados e para isonomia de tratamento aos sujeitos do processo, a realidade processual indica que esse discurso é meramente retórico e limitado ao plano teórico-abstrato, com dificuldades de se concretizar no plano prático-reformista. O trabalho é bibliográfico e desenvolve conceitos relativos à seletividade e às formas de controle do poder punitivo. Para abordagem do tema, partiu-se da perspectiva crítica do garantismo penal proposto por Luigi Ferrajoli.
\end{abstract}

Palavras-chave: Garantismo Penal. Seletividade. Criminologia Crítica.

\begin{abstract}
The present article deals with the effectiveness of individual guarantees and the reflection of this problem in access to brazilian criminal justice. In spite of the guarantees speech present the possible instruments for the defense of the accused and to equality of treatment to subjects in the process, the reality procedure indicates that this discourse is merely rhetorical and limited to theoretical plane-abstract, with difficulties to achieve practical-reformist. The work is bibliographic and develops concepts concerning the selectivity and the ways of controlling punitive power. To approach the subject, it was assumed the critical perspective of penal guaranteeism proposed by Luigi Ferrajoli.
\end{abstract}

Keywords: Criminal Guarantees. Selectivity. Critical Criminology.

Recebido em: 27/03/2016

Revisado em: 29/03/2017

Aprovado em: 31/03/2017 


\section{Introdução}

O presente trabalho buscou abordar a efetividade prática das garantias individuais invocadas no processo penal diante da postura estigmatizante e seletiva dos delinquentes na mira do controle penal. Para compreender a questão, inicialmente se procedeu à análise dos problemas relativos ao conteúdo discriminatório da justiça penal, pontuando a questão da seletividade pelo controle penal e os fatores preponderantes que sucumbem o delinquente à discriminação pela justiça criminal e pelas autoridades repressivas. Examinou-se também a força estigmatizante dos sistemas de controles penais na construção do estereótipo do "homem delinquente" e a forma como essa imagem é retroalimentada pela ideologia ${ }^{1}$ dominante.

Após discorrer sobre o conteúdo discriminatório da justiça penal, partiu-se para a abordagem dos crimes de "colarinho branco" com a finalidade de estabelecer o contraponto com os delitos convencionais e me-

\footnotetext{
${ }^{1}$ Oportuno frisar que a palavra "ideologia" utilizada neste trabalho tem como referencial de análise o materialismo histórico e dialético proposto por Karl Marx e Friedrich Engels. O termo "materialismo" é a afirmação do caráter social, concreto, ativo, produtivo da existência. A evolução histórica das sociedades ocorre pelos confrontos entre diferentes classes sociais, decorrentes da exploração do homem pelo homem. O materialismo histórico supera a metafísica e o individualismo racional filosófico, de forma que a história se perfaz na base econômico-produtiva da sociedade, na materialidade das relações produtivas. Marx supera a dialética idealista de Hegel e propõe uma dialética pautada no processo histórico de contradição da realidade, das próprias relações produtivas e práticas do homem ("negação da negação"). O direito se constitui pela necessidade histórica de as relações produtivas capitalistas estabelecerem determinadas instâncias que possibilitem a reprodução do sistema de exploração, ou seja, conforme as demandas capitalistas se impõem, os instrumentos jurídicos são criados. Nessa perspectiva, negase a neutralidade ideológica do direito. A responsabilização criminal é uma decorrência natural de certas estruturas econômicas, de maneira que o infrator seria vítima da luta de classes, mais especificamente resultado do determinismo social e econômico. Portanto, as bases ideológicas do direito penal seriam construídas pela classe social dominante. $\mathrm{O}$ crime, definido pela burguesia, também se modificaria com a natural transformação da sociedade. $\mathrm{O}$ poder que a classe dominante exerce sobre as pessoas está diretamente relacionado com a edificação ideológica que esta "elite" constrói dentro das mentes de seus dominados, fornecendo sua visão de mundo e transformando-os em objetos de uso e de exploração.
} 
lhor compreender o mecanismo de marginalização dos sujeitos passivos do processo penal.

A vulnerabilidade de alguns réus no acesso à justiça e a utilização sofisticada de instrumentos defensivos por uma parca parcela de outros acusados provocam questionamentos sobre a isonomia formalmente garantida na norma constitucional: tem a dogmática penal conseguido garantir os direitos humanos individuais contra violência punitiva? Tem sido possível controlar o delito com igualdade e segurança jurídica? Encontra congruência na operacionalidade do sistema penal o discurso garantidor em nome do qual a dogmática penal fala e pretende legitimar o seu próprio ideal de ciência? E é, pois, pelo cumprimento da função racionalizadora e garantidora declarada que se explica sua marcada vigência histórica, ou ela potencializa e cumpre funções distintas das prometidas?

A falácia da dogmática penal provém de uma interpretação corriqueiramente utilizada para garantir a manutenção do poder da ideologia dominante e não como instrumento garantidor da efetividade dos direitos do acusado marginalizado pelo sistema vigente.

O objetivo do trabalho foi apresentar o problema do acesso às garantias penais pelos indivíduos excluídos socialmente, a fim de retratar as dificuldades de "alguns" e a facilidade de "outros" em exercer a ampla defesa nos moldes previstos no texto constitucional.

\section{Discriminação da Justiça Penal e o Estereótipo do Homem Criminoso}

A ideologia propagada pela indústria penal é a de que o público deve ser protegido contra a violência dos criminosos, sob o argumento, altamente reproduzido pelo senso-comum, de garantir a segurança jurídica da coletividade. A perpétua sensação de crise auferida pelos anseios populares e o medo incutido na sociedade (em parte provocados e dramatizados pela mídia e os meios de comunicação em massa) disseminam o paradigma do fracasso na justiça criminal ("nada funciona"), ou seja, influenciadas pelos resultados da crescente taxa de criminalidade e tam- 
bém por um espraiado sentimento de desilusão e pessimismo, as instituições passaram a ser vistas como ineficientes ou contraproducentes (GARLAND, 2008, p. 155).

Para resgatar a credibilidade nas instituições, a prisão torna-se o principal instrumento de contenção neutralizante, como bem salienta David Garland (2008, p. 59):

Em nítido contraste com a sabedoria convencional do período passado, a opinião dominante agora é a de que "a prisão funciona" não como um mecanismo de reforma ou de reabilitação, mas como instrumento de neutralização e de retribuição que satisfaz as exigências políticas populares por segurança pública e punições duras.

Esse é o cenário do atual sistema penal, o qual exerce seu controle por meio da produção de normas jurídicas mais severas (hiperpunitivismo legislativo) e da potencialização do aparelho repressivo (julgadores) direcionados para uma categoria homogênea de criminosos, evidenciando o perverso caráter discriminatório da justiça penal.

Vislumbra-se na lógica do controle penal pela ordem formal a discriminação da justiça, tanto na órbita legislativa, com os sujeitos passivos devidamente delimitados pela tipicidade da conduta, quanto na aplicação das leis pelos julgadores, por meio da obediência às tendências sistêmicas e da padronização das decisões, resultando no etiquetamento do delinquente.

No que tange à discriminação na produção das leis, é interessante notar que as leis são frutos da atividade humana e, dessa forma, torna-se idealização de um grupo social com o propósito de assegurar a conservação do seu status quo socioeconômico. De acordo com Augusto Thompson (2007, p. 47):

Numa sociedade complexa e hierarquizada, dita as leis a classe que dispõe de poder. E, obviamente, armará a ordem legal de sorte a garantir a permanência das desigualdades existentes, das quais decorrem vantagens que lhes bafejam os membros, tanto quanto o onus suportado pelas massas oprimidas. 
Forçoso concluir que crime e criminoso não são entidades absolutas (BECKER, 2008, p. 21-22), mas tão somente resultado da vontade do legislador, o qual limita as figuras delituosas justamente para impedir a apenação de ações que, seletivamente, não lhe interessa perturbar. É bem dizer que as prescrições punitivas de caráter elástico prejudicam o interesse de uma determinada classe social, de maneira que será criminoso o indivíduo que observar no mundo fático uma conduta precisamente adequada ao modelo abstrato prefixado em artigo de lei; ocorrendo descoincidência em algum ponto, descaracterizado restará o delito, por ausência de tipicidade.

A título de exemplo, oportuna análise do tipo penal de estelionato. Levando ao pé da letra os elementos contidos da descrição do tipo, a indústria e o comércio entrariam em colapso, uma vez que é comum nas propagandas comerciais um induzimento a erro mediante artifício ao consumidor. Para a sociedade burguesa, tal conduta se revelaria um insuportável despautério, quando muito o conflito se resolveria no âmbito civil (THOMPSON, 2007, p. 51).

Ainda na seara pragmática, a ideologia dominante convence ser crime de conduta típica de pessoas pobres e reforça o estereótipo do criminoso: a sonegação fiscal, delito classificado como "crime contra a ordem tributária", admite a extinção da punibilidade quando restituído o valor subtraído antes do recebimento da denúncia, conforme previsão do artigo 34 da Lei n. 9.249/95; o tipo de furto também possui como objetivo punir condutas que visam à dilapidação do patrimônio alheio, no entanto, o benefício da extinção da punibilidade não se aplica quando o produto ou valor é devolvido antes do recebimento da exordial acusatória.

Percebe-se uma escancarada preferência legislativa em criminalizar os autores de crimes contra o patrimônio, em sua maioria pobre, enquanto se imunizam comportamentos típicos de indivíduos pertencentes às classes dominantes, como a sonegação fiscal.

Além da nítida discriminação legislativa, há também a discriminação na aplicação da lei pelas instituições estatais repressivas. Rogério Dutra (2015), em pesquisa realizada em alguns estados brasileiros, constatou que mais de $90 \%$ dos acusados da Bahia e $80,4 \%$ dos acusados de 
Santa Catariana respondem ao processo presos. Segundo o autor, existe uma criminalização artificial (porque produzida em geral de forma ilegal) de parcelas significativas de jovens negros das periferias das grandes cidades, que movimenta de forma perversa as verbas públicas da área de segurança, de maneira que, quanto maior o sistema carcerário, maior será a quantidade de licitações, financiamentos e negócios realizados. Isso significa que o sistema repressivo se orienta pela lógica do lucro e não pelos benefícios que seu correto funcionamento poderia trazer para a sociedade.

Michel Misse (2011, p. 22) pontua que os aparelhos repressivos se orientam pela posição de classes, formadas historicamente, para selecionar as práticas criminosas:

O crime pode ocorrer em qualquer classe, estrato ou fração estamental, mas existem diferenciais históricos de designação e perseguição de certas ações como criminais, como também da orientação dos aparelhos que cuidam de sua detecção e resposta punitiva, que podem ser determinados, numa medida significativa, em correlação com as posições de classe, estrato ou de frações estamentais.

O Censo Penitenciário do Brasil confere o padrão dos frequentadores das penitenciárias brasileiras: $97 \%$ homens, $95 \%$ pobres, $68 \%$ entre 18 e 25 anos, $89 \%$ sem trabalho fixo, $76 \%$ analfabetos ou semialfabetizados, $65 \%$ negros ou mulatos. Tal estereótipo é construído pelo fato de que os aparelhos de resposta ao crime selecionam mais certos tipos de ação e de agente, do que outros; que os crimes selecionados são também os que provocam maior reação moral e social; que os crimes que provocam maior reação moral e social são os chamados crimes violentos, aqueles cujos agentes, dispondo ou não de outros meios de poder, utilizam-se da coação física imediata (ou sua ameaça), ou que executam o aniquilamento físico do outro em seu desenvolvimento; que os agentes "pobres" (ou com parcos recursos alternativos) que operam diretamente a ação criminal, por limitação social na escala da seleção de meios e de preferências criminais, mas também por outras razões, tendem a estar mais sujeitos ao emprego da violência como meio criminal (MISSE, 2011, p. 23). 
Merecem destaque dois fatores preponderantes que sucumbem o delinquente à discriminação pela justiça criminal e pelas autoridades repressivas: a) maior visibilidade da infração; b) adequação do autor ao estereótipo do criminoso construído pela ideologia prevalente (THOMPSON, 2007, p. 60).

Comumente percebido na fase policial, a infração será mais visível na medida em que ocorra num lugar com respeito ao qual a polícia dispõe de maior facilidade de acesso, tanto em termos de espaço quanto de tempo. A fiscalização dos órgãos de segurança incide com maior incidência nos logradouros públicos (ruas, praças, parques, etc.) e nas moradias situadas nas favelas, barracos e demais locais extremamente devassáveis. A parcela pobre da população permanece a maior parte do tempo em franca exposição. Do contrário, o acesso policial não encontra a mesma facilidade em recintos com ingressos limitados (condomínios fechados, prédios, apartamentos, etc.), visto que precisa respeitar a seleção desejada dos moradores.

Some-se, ainda, a dificuldade de apurar tais delitos: primeiro, o acesso a ambientes fechados exige o mandado de busca e apreensão, como garantia constitucional da intimidade dos moradores; em segundo, alguns delitos são praticados com sofisticação tecnológica e necessitam da quebra de sigilo bancário e telefônico, os quais apenas são fornecidos mediante ordem judicial fundamentada. Nesse ponto, já se nota também traços da seletividade do discurso garantista, o qual será oportunamente analisado mais a frente.

Outro elemento discriminante é a construção do estereótipo do homem criminoso pela ideologia prevalente. Os casos que chegam à agência judicial são produto de uma seletividade estrutural, incialmente filtrados no contínuo controle social exercido pelas agências policiais. O filtro utilizado é o que se critica: na atividade policial concentra-se a vigilância sobre indivíduos considerados mais propensos a desrespeitar a lei; logo, nas rotineiras "batidas policiais", os policiais selecionarão de acordo com a ideia que possuem a respeito de quem é o criminoso e no que vivenciam no cotidiano (THOMPSON, 2007, p. 65). 
A composição do estereótipo do delinquente também é realizada pela ideologia do contrato social. O raciocínio popular é o de que a sociedade é essencialmente justa e, se há pessoas capazes de desrespeitar as regras básicas, forçoso reconhecer que tais desviantes são anormais. E a anormalidade está ligada não ao que pessoa $f a z$, mas ao que ela é. Dessa forma, mesmo sem dispor de informação convincente acerca da prática por parte de dado indivíduo, de um fato preciso, contemplado como típico pela lei penal, reconhecê-lo-emos como delinquente se: pertencendo à classe inferior apresenta registros policiais, o que é apurável por meio das indicações mais visíveis relativas à cor (preto ou mulato), aspecto físico (falhas de dentes, mãos e pés grandes, feições abrutalhadas, olhar oblíquo), baixa escolaridade (linguagem pobre, pejada de gírias), morador em favela, membro de família desorganizada ou sem família, sem emprego ou subempregado.

Apesar dos fortes traços marginalizantes apresentados em sede policial, oportuno salientar que a seletividade penal também se apresenta na fase judicial. Diante da individualização de condutas e a pluralidade de situações fáticas existentes no processo penal, a fundamentação das decisões judiciais deveriam ser produzidas com maior atenção às garantias constitucionais. Contudo, a uniformização e a previsibilidade dos julgados funcionam como instrumentos selecionadores do sistema, a depender do status social e das exigências do poder constituído do acusado. Assim, a igualdade formal aparece como desigualdade real.

Além disso, a prerrogativa do livre convencimento motivado (ou da persuasão racional) do magistrado e o princípio do in dubio pro reo são discursos corriqueiros na prática processual penal, porém, podem possuir caráter discriminatório ao garantir um poder discricionário e amplo ao juiz no julgamento. A discricionariedade, inclusive, encontra respaldo legal no artigo 59 do Código Penal ${ }^{2}$, o qual prevê critérios amplos ao magistrado para fixação da pena e proporciona um alto nível de subjetivismo nas motivações da decisão.

\footnotetext{
2 Art. 59. O juiz, atendendo à culpabilidade, aos antecedentes, à conduta social, à personalidade do agente, aos motivos, às circunstâncias e consequências do crime, bem como ao comportamento da vítima, estabelecerá conforme seja necessário e suficiente para reprovação e prevenção do crime.
} 
Por mais técnica que seja uma decisão judicial, inegável que ela possua uma ideologia prevalente, a qual fica isenta de motivação fática e jurídica pelo julgador. Vera Regina Pereira de Andrade (2012, p. 224-225) pontua:

O second code (código ideológico latente) judicial é o que geralmente pauta e condiciona, efetivamente e a priori, as decisões, mas não se submete à obrigação de motivação fática e jurídica da sentença, permanecendo, por isso, invisível e fora do controle público. [...]. Ora a sentença penal é muito mais complexa do que uma exclusão/imputação de responsabilidade penal baseada nos códigos legais e no código tecnológico dogmático, os quais, ao serem invocados, não cobrem nem revelam o second code judicial, nem os processos de influência que, excluídos e predominados sobre aqueles, condicionam real e latentemente a seletividade das decisões judiciais.

Rosa Maria Cardoso Cunha (1979, p. 120) sintetiza bem o problema do estereótipo subjetivamente construído e retroalimentado pela ideologia dominante ao se condenar uma pessoa, ao afirmar que nas decisões judiciais não há raciocínios teoréticos, mas opções eticamente comprometidas que, por sua vez, já se apoiam em escolhas probatórias valorativamente determinadas. Assim, no discurso jurídico-penal, o critério de derivação é axiológico e não demonstrativo.

Ademais, o estigma de criminoso e vítima está associado à "teoria de todos os dias", a qual explica que a convicção judicial se constrói a partir da observação das repetidas condutas desviantes, a ponto de ser possível encontrar um padrão tendente à posição social do acusado:

A regularidade da distribuição seletiva da criminalidade (imunização e impunidade versus criminalização) e particularmente das decisões judiciais seletivas é explicada pela influência de um código social (second code) latente, integrado por mecanismos de seleção, entre os quais se destacam: (a) a importância central dos estereótipos de criminosos e vítimas associados às teorias de todos os dias (every days theories), dos quais são portadores os juízes e a opinião pública; (b) os processos derivados da estrutura organizacional e comunicati- 
va do sistema penal, que reenviam ao status social do processado, em detrimento do instrumento dogmático construído para a imputação da responsabilidade penal, que deveria reenviar à sua conduta (Direito penal do fato ou ato). (ANDRADE, 2012, p. 223)

O insuficiente conhecimento e capacidade de penetração no mundo do acusado, por parte do juiz, leva-o, inconscientemente, a tendências de juízos diversificados, a depender da posição social do acusado (BARATTA, 2002, p. 177).

Justificada a desigualdade existente na justiça penal vigente, torna-se possível compreender quem são os "protagonistas" (leia-se, sujeitos passivos) desse sistema. Essa análise de criminosos será fundamental para verificar a seletividade das garantias individuais inerentes ao processo penal.

\section{Os Crimes de "Colarinho Branco": características e elementos diferenciadores dos delitos convencionais}

Observa-se no sistema penal brasileiro uma segregação de classes de criminosos: de um lado, os delinquentes com alto poder econômico, social ou cultural, cujas condutas punidas, conhecidas como crime do colarinho branco, possuem características diferentes dos criminosos das camadas sociais menos abastadas.

A denominação crimes de "colarinho branco", também conhecido como "white colar crime", surgiu com os estudos de Edwin Sutherland. Contudo, já na década de 1930, antes de Sutherland, Morris havia diagnosticado essa classe de criminosos, ao denominá-los de "criminosos da alta sociedade". Segundo a definição de Sutherland, é o delito cometido por uma pessoa de respeitabilidade e status social alto no curso de sua ocupação (SANTOS, 2006, p. 1.152).

De acordo com o próprio Sutherland, o termo "colarinho branco" foi utilizado para designar, sobretudo, os dirigentes e administradores de empresas, conforme o significado que o presidente da General Motors havia atribuído em sua obra "An autobiography of a White Collar Worker". 
O termo white collar é uma referência ao colarinho típico dos trajes a rigor, vestimenta essa assimilada às pessoas bem sucedidas, que ostentam poder no seio social (powerfull), transmitindo a ideia de prestígio político e financeiro, em exata oposição à expressão blue collar, relativa aos operários (social work) que vestiam macacão na cor azul (MASSUD, 2012).

Muitas críticas foram feitas a esse conceito: inicialmente, a falta de critérios para se conceituar "pessoa respeitável", considerando a diversidade cultural existente nas variadas sociedades. Em segundo lugar, a dificuldade em delimitar o que venha ser "elevada condição social", diante dos vastos fatores político-sociais que tornam o conceito demasiadamente aberto para que se possa estudar o fenômeno a partir de dados estatísticos. Por fim, em relação à característica "no curso de sua ocupação", esta, por si só, não aproveita ao estudo do fenômeno, haja vista que excluiria toda e qualquer pessoa que, não obstante preenchesse todas as características anteriores, tivesse cometido a conduta no âmbito de sua vida privada (SANTOS, 2001, p. 193).

Apesar das críticas, é oportuno ponderar que Sutherland era sociólogo e não conhecia as particularidades da dogmática jurídica, por isso, procurou explicação teórica mais generalizável e eficaz para a pergunta óbvia que rondava a criminologia na década de 1940: o que acontece com os ricos?

Quando os juristas lêem Sutherland, devem fazê-lo com uma série de reservas que tornem mais compreensível seu pensamento. Em primeiro lugar, não raciocinava como advogado, mas, sim, como sociólogo, e, por consequência, não se valia de uma noção dogmática e legal de conduta delitiva e, em vez disso, pura e simplesmente, construiu um conceito de delito para sua investigação, sem levar em conta se as condutas escolhidas estavam tipificadas ou não em algum código penal; assim, Sutherland considera que o delito é uma conduta que reúne determinados parâmetros de lesividade social. (ELBERT, 2009, p. 164)

A dificuldade existente para marcar os limites conceituais reside no fato de que os crimes de colarinho branco possuem objeto de estudo resis- 
tente a uma definição dogmática e, além disso, apresenta contínuas transformações em sua fenomenologia.

Entretanto, o citado autor norte-americano modificou o panorama estatístico sobre a criminalidade e o rumo dos estudos desse fenômeno, demonstrando que os ricos e poderosos cometem crimes com muito maior frequência do que se cogitava até então. Pode-se arriscar a dizer que o grande impacto causado pelos estudos e as afirmações de Sutherland residiu na quebra da noção comum que se tinha de criminoso e da própria noção de crime, ao dar o primeiro passo para desvincular a criminologia da dogmática jurídico-penal. Mostrou-se que o criminoso não pertencia a uma "espécie" diferente, fosse ela biológica ou social. Democratizou-se, a partir de então, a figura do delinquente, que não mais pertencia às chamadas classes perigosas, atribuídas inicialmente aos criminosos ordinários. Elbert (2009, p. 166) deixa clara a contribuição de Sutherland para compreensão do novo padrão de sujeito criminoso que se verifica no meio social:

A partir da obra comentada, as bases da Criminologia estabelecida começaram a mudar irrefreavelmente. Desmistificaram-se os pilares essenciais do Direito Penal e da Criminologia tradicional: reconheceu-se que a sociedade não funcionava nem consensual, nem igualitariamente, porque a lei não alcançava todos os setores por igual; o problema básico da conduta delinquente não radicava nem na doença nem na autodeterminação, mas sim na forma de estruturar e atuar o direito; os bens juridicamente tutelados não eram necessariamente os mais importantes; o Direito Penal perdia seu caráter de moral social igualitária; o bem e o mal eram mais ubíquos que o imaginado; e tampouco as reações penais funcionavam de igual modo para todos, nem podiam explicar-se por propósitos ressocializadores. E como corolário notável, tirava-se a explicação do fenômeno criminal das mãos de penalistas, alienistas, biólogos, psicólogos, para depositá-la nas dos sociólogos.

Os autores do white collar crime apresentam características específicas, as quais os diferenciam do criminoso comum. Segundo Sutherland, o comportamento criminal destes delinquentes nasce do aprendizado pelo 
maior contato com indivíduos que transmitem a ideia de que tal comportamento apresenta mais aspectos favoráveis que desfavoráveis do que com aqueles que transmitem a ideia contrária, teoria essa conhecida como associação diferencial.

Para colmatar as lacunas que sobrevieram a esta sua teoria, Sutherland desenvolveu outra linha de pensamento por meio da teoria da desorganização social. O autor procedeu à verificação da diferente distribuição do crime pelos vários grupos sociais, por forma a explicar o aparecimento referencial do crime nas comunidades onde os vínculos fossem mais ténues e constatou que a explicação para este fenômeno seria o menor controle social em grupos determinados que faria com que, posteriormente, esses mesmos grupos aparecessem em grande número nas estatísticas criminais. Essa desorganização, no seu entender, poderia ser explicada por um lado pela complexidade e tecnicidade dos comportamentos negociais e, por outro lado, pela rapidez das mudanças sociais que potencializam os conflitos de valores (SANTOS, 2006, p. 1.154-1.155).

Além da aprendizagem inerente às associações diferenciais, a conduta criminal deve trazer uma conotação positiva e, principalmente, uma identificação com a pessoa que a pratica. Nas sociedades competitivas, o critério de sucesso pode constituir um elemento suficiente para identificação, o que Franco Ferracuti (1970, p. 263) chamou de identificação criminal.

Entretanto, a característica fundamental dos crimes de colarinho branco são as técnicas de neutralização. Essas técnicas explicam como alguns fatores psicossociais influenciam no juízo de censura do delinquente, ou seja, como a violação legal pode se tornar algo aceitável e, por vezes, até recomendável. As técnicas de neutralização encerram um paradoxo, pois explicam e exculpam condutas sem comprometer a sua adesão aos valores tradicionais e dominantes. Isso faz com que o delinquente não se sinta criminoso. Dentre as diversas técnicas possíveis, existem cinco tipos essenciais (MASSUD, 2012).

A primeira técnica seria a negação da responsabilidade, ou seja, nega a identificação da autoria com os fatos e a atribui a circunstâncias irresistíveis. Exemplo é o empresário que, diante da crise econômica ou 
queixando-se da excessiva carga tributária, legitima sua conduta de sonegar impostos. O infrator não nega a validade da norma, mas defende-se sugerindo que diante da situação casuística, não se podia exigir seu cumprimento e, portanto, exime sua culpa. Teoria conhecida como inexigibilidade de conduta diversa.

A segunda técnica seria a negação do dano, ou seja, o agente nega a ocorrência de resultado naturalístico relevante, em razão da ausência de prejuízo ou da devolução do objeto tutelado penalmente, comum nos casos de vítima abstrata ou nos crimes sem vítima. Essa técnica é utilizada nos crimes de lavagem de dinheiro, falsificação de documentos pessoais, estelionato, fraude à bolsa de valores, etc.

A terceira técnica seria a negação da vítima, ou seja, nega-se a existência da condição de vítima ou anula suas qualidades positivas que poderiam gerar o sentimento de identificação, simpatia e culpa. Exemplo: crimes cometidos contra grupos marginalizados (prostituta, mendigo, homossexuais e outros). Muito comum nos crimes contra a propriedade intelectual e nos crimes contra o consumidor. O comportamento do Estado (vítima) gera antipatia no mercado consumidor e na sociedade, de forma a legitimar a conduta criminosa.

A quarta técnica seria a condenação dos condenadores, ou seja, baseia-se na concepção de que a lei penal em determinados casos é injusta, transportando a reprovabilidade do comportamento delinquente para o Estado. A conduta punida não é tida como legítima pela sociedade.

A última técnica seria o apelo a lealdades superiores, ou seja, algumas condutas são praticadas em nome de valores que estariam acima da norma. Exemplo é a corrupção policial com a finalidade de que eles priorizem a segurança em sua residência ou de seu estabelecimento comercial, justificando a conduta diante da ausência estatal.

Além das técnicas de neutralização já esboçadas, outros fatores explicam a desigualdade de tratamento. Um fator que se destaca é a dificuldade enfrentada pela dogmática jurídico-penal para a construção de tipos penais diante da complexidade de condutas, as quais evolvem bens jurídicos supraindividuais intrinsicamente ligados a aspectos da realidade eco- 
nômica. Condutas complexas que se revestem da aparência da legalidade e tornam a criminalidade do colarinho branco menos visível.

Impõe-se lembrar que a maioria das infrações praticadas pelos indivíduos socialmente privilegiados fica ao abrigo da escuridão da "cifra oculta"3, sequer chegando à ciência da polícia, porta de entrada da ordem formal (THOMPSON, 2007, p. 56).

Outro fator relevante é que os criminosos ricos evitam invocar as organizações ordinárias da justiça penal, pois levar ao conhecimento da justiça criminal geraria a impressão de que seus componentes são tão ordinários como os representantes da população menos abastada. Quando muito, os litígios se encerram no âmbito civil.

A corrupção também é um fator de desequilíbrio na forma de aplicação da lei penal entre o white collar e os demais criminosos. O corruptor não quer abrir mão de descumprir a lei por uma vantagem que o beneficia, na maioria das vezes economicamente. E, diante da facilidade financeira apresentada, o corrupto não quer perder aquela fonte de renda. Logo, cria-se essa teia de relações que dificultam descobrir a conduta delitiva. Thompson (2007, p. 77) apresenta argumento crítico acerca do assunto, ao afirmar que há um direcionamento na opinião pública para convencer a população de que a corrupção é produto da má gestão administrativa ou de mero acidente na tentativa de evitar questionamentos sobre a validade do próprio sistema.

Por derradeiro, oportuno salientar o corpo jurídico que atua em favor desses criminosos garante uma defesa técnica pormenorizada e eficiente. Porém, esse assunto será discutido no tópico seguinte, juntamente com a análise da seletividade do garantismo penal.

\footnotetext{
${ }^{3}$ Alguns autores apontam para a existência de dois tipos de "cifra oculta": a "cifra negra" e a "cifra dourada", a primeira estaria relacionada aos delitos convencionais que não chegam ao conhecimento das autoridades penais. A segunda estaria relacionada às infrações penais praticadas pela elite, não reveladas ou apuradas. A "cifra dourada" representa a criminalidade de "colarinho branco" oculta (crimes fiscais, eleitorais, políticos, etc.), definida como práticas antissociais impunes do poder político e econômico (a nível nacional e internacional), em prejuízo da coletividade e dos cidadãos e em proveito das oligarquias econômico-financeiras.
} 


\section{Garantismo Penal para Quem?}

Sustentada na dogmática penal, a teoria garantista representa ao mesmo tempo o resgate e valorização das normas constituintes como elementos fundamentais para limitar os abusos estatais rotineiros na demanda penal. Logo, as bases teóricas do garantismo constituem instrumentos estratégicos para mitigar os abusos que o Estado Penal comete contra os excluídos sociais, mais especificamente para defender e bem equacionar o constitucional Estado Democrático de Direito.

$\mathrm{O}$ discurso garantista tem por base o respeito à dignidade da pessoa humana e seus direitos fundamentais, com sujeição formal e material das práticas jurídicas aos conteúdos constitucionais.

Luigi Ferrajoli (2002, p. 683-685) atribui três significados conexos à expressão "garantismo". Na primeira concepção, o garantismo é um modelo normativo legítimo do Estado de Direito e implicaria uma limitação estatal punitiva pelos comandos constitucionais. Na segunda concepção, teoria jurídica da validade e da efetividade, a qual se expressa como uma técnica de aproximação entre a existência formal da norma jurídica com a sua efetiva concretização. Na terceira concepção, o garantismo se apresenta como uma filosofia política que requer do direito e do Estado o ônus da justificação externa com base nos bens e interesses dos quais a tutela ou a garantia constituem a finalidade.

Sob o enfoque do destinatário, o garantismo penal tem a finalidade de respaldar os vulneráveis em relação aos mais fortes, com as garantias exprimindo os direitos fundamentais dos cidadãos contra os poderes do Estado, os interesses dos fracos respectivamente ao dos fortes, a tutela das minorias marginalizadas ou dissociadas em relação às maiorias integralizadas. A partir do garantismo passa a se considerar o delinquente como sujeito de direitos (BIZZOTTO, 2009, p. 76).

Todavia, o que se põe em xeque é se o modelo teórico abstrato proposto pelo discurso garantista consegue romper as barreiras da mera retórica dos direitos fundamentais e se efetivar no campo pragmático. Logo, questiona-se: dentre o catálogo de garantias possíveis de serem invocadas 
no processo penal, será que todos os acusados têm a real possibilidade de efetivá-las com o amplo acesso à justiça?

A resposta parece ser negativa. Diversas críticas são feitas com relação ao garantismo penal.

A primeira crítica que surge é que a fundamentação garantista é legitimadora do sistema penal, pois a falta de demonstração empírica sobre a idoneidade preventiva da pena permite dizer que a legitimação conferida pelo garantismo à pena pode significar, de certa forma, uma ampliação do sistema penal (BIZZOTTO, 2009, p. 98-99).

Além disso, o modelo garantista não consegue ultrapassar os limites da dogmática penal, desenvolvendo suas interpretações com a crença na racionalidade normativa. Esse mesmo sistema normativo se constitui em um "sistema de garantias artificialmente preordenadas à tutela dos direitos fundamentais". Assim, a promessa de racionalização do poder punitivo do Estado, com base no tecnicismo jurídico, está vinculada aos ideais burgueses para legitimação e operacionalização do sistema jurídico (ANDRADE, 2012, p. 208).

Outra crítica é que a idealização constitucional dos direitos humanos, sem a força e o compromisso para aplicação do discurso garantista, mostra a interpretação normativa frágil e de alcance limitado:

A falta de compromisso interpretativo com a efetividade das garantias, seja pela passividade ao se aceitar a mera legalidade desvinculada do sentido justificador da limitação da intervenção punitiva, seja pela falta de resistência para se manter o teor de proteção aos avanços do Estado Penal contido no texto normativo, torna as disposições legais objeto de manipulação na interpretação, esvaziando-se a amplitude de proteção penal, com a limitação da concepção sobre o seu alcance sem que a mesma seja avaliada como estranha aos objetivos garantista. (BIZZOTTO, 2009, p. 130)

A perniciosidade no uso do discurso garantista encontra guarida nas proposições que se afirmam garantistas, mas que na prática (discursiva ou jurisdicional) não passam de orientações formalistas, na medida em que deixam concretamente a proteção ao ser humano em segundo plano. Há 
uma apropriação dos discursos garantistas com resultados interpretativos jurisdicionais que dão aparência de legitimidade aos abusos punitivos.

Por meio das críticas expostas e, até mesmo diante do conteúdo discriminatório do sistema penal anteriormente pontuado, percebe-se a existência de certa blindagem por parte do discurso garantista a determinados sujeitos do processo penal, de forma que o acesso à justiça torna-se instrumento de exclusão, com a efetiva participação processual por uma pequena parte dos acusados.

A seletividade das garantias fica evidente no que tange ao exercício da defesa perante a justiça penal: de um lado, a vulnerabilidade 4 dos delinquentes pobres para apresentar defesa técnica e, até mesmo, sua dificuldade em compreender as informações processuais e os direitos que lhe tutelam, e de outro, a sofisticação ${ }^{5}$ dos delinquentes de colarinho branco em contratar bons advogados desde a fase inquisitiva, evitando-se a autoincriminação e as confissões arbitrárias e estruturando a defesa sem vícios.

Raro o caso em que uma pessoa classe média para cima comparece na delegacia de polícia desacompanhada de advogado, pois ainda que se dispense sua presença, o defensor poderá impedir que seu cliente sofra violências e arbitrariedades, posto que sua presença infundirá receio aos policiais de virem a ser punidos pelo emprego da tortura; manipular convenientemente os autos, a ponto de, com sua competência e expertise, retirar o máximo de proveito para que constar ou omitir palavras no interrogatório de seu cliente (THOMPSON, 2007, p. 78-79).

\footnotetext{
${ }^{4}$ Ana Gabriela Mendes Braga (2013, p. 33-35) afirma que o termo vulnerabilidade está associado à exposição e à susceptibilidade das pessoas a determinados riscos. Dentre os riscos que envolvem esse tipo de vulnerabilidade estão o desemprego, a desestabilidade familiar, a marginalidade, e consequentemente, o encarceramento. A vulnerabilidade individual é proporcional ao risco do indivíduo ser selecionado pelas agências do sistema de controle, seja por fatores exteriores a sua vontade (condição socioeconômica) seja a partir da autocolocação em risco a partir de determinados comportamento.

${ }^{5}$ Em contrapartida à vulnerabilidade, pode-se colocar o conceito de sofisticação, o qual constitui na capacidade de conhecer a conduta dos atores do sistema de controle e de manipular a própria conduta a partir desse conhecimento, de forma a dificultar a criminalização (BRAGA, 2013, p. 35).
} 
O poder da defesa é elemento fundamental para se efetivar as garantias individuais no processo penal:

É inegável que a atuação de um bom advogado (na maioria das vezes inacessível àqueles que não têm como pagar) numa causa criminal pode contribuir para um aumento das chances de absolvição, prescrição ou a obtenção de outros benefícios legais. A atuação dos advogados, especializados na área criminal, desde os primeiros momentos da investigação - geralmente são advogados constituídos certamente, incrementam, em muito, as possibilidades de sucesso na causa, seja com uma atuação dentro dos limites legais (orientando o cliente quanto à versão a ser dada para os fatos; evitando que o cliente venha a produzir prova contra si mesmo, muitas vezes produzindo provas favoráveis ao seu cliente, etc.) ou não (corrupção de agentes públicos). (MASSUD, 2012)

A ampla defesa necessita ter um significado substancial com a concretude do caso penal. Não adiantam discursos constitucionais abstratos se, efetivamente, há lesão ao direito de fala do imputado. Vale ressaltar que o defensor não é um auxiliar do juiz ou da justiça. $\mathrm{O}$ que poderia ser afirmado em um sentido figurado ou metafórico. Não cabe a defesa ser dócil com as conveniências estatais, com as vontades judiciais ou com as pretensões acusatórias, tampouco o Estado utilizar a presença de defensor para legitimar as formalidades processuais. Isso é uma inversão ideológica do discurso garantista (BIZZOTTO, 2009, p. 167-168).

Para defesa dos interesses dos hipossuficientes, a norma constitucional garante a participação da Defensoria Pública, instituição permanente e essencial à função jurisdicional do Estado, cuja participação atuante e combativa é evidente no processo penal.

O grande problema é que a demanda criminal atinge montantes espantosos aos defensores públicos, justamente em razão da seletividade das condutas penais. Para exemplificar, em entrevista realizada com o advogado Antonio Carlos de Almeida Castro, conhecido como Kakay, famoso por defender criminosos do "colarinho branco" como Duda Mendonça (2014) no emblemático caso do Mensalão, interessante notar sua forma de atuação: 
No escritório conto com mais três advogados e dispenso muitas defesas. De cada trinta casos, pego somente um. Eu faço todos os casos, discuto com os advogados do escritório, dou e defino a linha de atuação, faço a sustentação oral, distribuo memorial, então não dá para ter muitos processos.

Há poucos defensores para enorme quantidade de acusados nos processos penais. Saliente-se que, conforme dados do Ministério da Justiça ${ }^{6}$, em 2006, 71,30\% das verbas foram destinadas ao Judiciário, enquanto 25,37\% ao Ministério Público e 3,33\% à Defensoria Pública. Em 2009, o III Diagnóstico da Defensoria Pública do Brasil $^{7}$ apurou que com relação ao orçamento total dos Estados, o Judiciário ficou com 5,34\%, o Ministério Público com $2,02 \%$ e a Defensoria Pública com a ínfima participação orçamentária de $0,40 \%$.

Oportuno considerar que em boa parte das comarcas não há defensores públicos, o que agrava demasiadamente o direito de defesa, ao sucumbir o acusado "a sorte" da nomeação de um defensor dativo competente, muita das vezes indicado por conveniência judicial e formal:

[...] boa parte daqueles alcançados pelo sistema penal são pessoas de poucos recursos econômicos, que necessitam de defensor dativo nomeado pelo juiz. Percebe-se uma falta de critérios previamente estabelecidos para a escolha. Muitas vezes, o magistrado indica profissionais que se colocam mais à disposição de auxiliar o ritmo do Juízo, o que permite a condução do processo conforme a conveniência judicial. Pode-se dizer então que, na situação narrada, através da perseguição de uma finalidade teórica de se tutelar a defesa e suas garantias, a atuação do juiz pode se direcionar para a obtenção de resultado punitivo. A livre nomeação pelo magistrado fere a ideia da imparcialidade. (BIZZOTTO, 2009, p. 184-185)

${ }^{6}$ Disponível no sítio: <http://www.anadep.org.br/wtksite/downloads/Diag_defensoria II.pdf $>$ Acesso em: 10 out. 2014.

7 Disponível no sítio: <http://www.anadep.org.br/wtksite/IIIdiag_DefensoriaP.pdf $>$. Acesso em: 10 out. 2014. 
Rogério Dultra (2015) reconhece o poder dos direitos e garantias processuais penais limitar a atuação do poder repressivo do Estado. O problema é que o próprio sistema penal viola esses direitos e garantias, na medida em que milhares de pessoas são mantidas presas, sem culpa provada e tampouco conjunto probatório mínimo que sustente processualmente a prisão. Justifica o autor que o sistema judicial se burocratizou e se automatizou, de forma que o juiz de primeiro grau não se sente diretamente responsável pela decretação da prisão preventiva. Além disso, Dultra (2105) ressalta que o excesso de prisão provisória, especialmente no núcleo duro da prisão (crimes contra o patrimônio e tráfico de drogas), ocorre justamente pela inconsistência da defesa ou da ausência de resistência.

Há ainda outro critério de seleção dos criminosos, produzido pelo poder legiferante, mas com efeito no âmbito jurisdicional: as regras de competência para julgamento dos delitos. Consoante previsão Constitucional (artigo 109, inciso I), a competência será sempre federal se a infração penal for praticada em detrimento de bens, serviços ou interesse da União; crime político; crime ambiental praticado em locais pertencentes à União; crimes contra o sistema financeiro, a ordem econômico-financeira e a lavagem de dinheiro; crimes praticados a bordo de navios e aeronaves; crimes contra a organização do trabalho; além dos crimes tipificados na legislação comum ou especial que também sejam previstos em tratado ou convenção internacional, desde que haja um nexo de internacionalidade, tais como: crime de tráfico internacional de entorpecentes (Convenção contra o tráfico ilícito de entorpecentes e substâncias psicotrópicas); crime de tráfico de mulheres (Convenção para repressão ao tráfico de pessoas e do lenocínio, de Lake Sucess, EUA); crime de tortura (Convenção contra a tortura e outros tratamentos ou penas cruéis, desumanos ou degradantes); crime contra a população indígena (Convenção n. 107, sobre a proteção e integração das populações indígenas e outras populações tribais e semitribais de países independentes); crime de guarda de moeda falsa (Convenção Internacional para a repressão de moeda falsa); crime de pornografia infantil e pedofilia (Convenção sobre os direitos da criança); crimes de corrupção ativa e tráfico de influência nas transações 
internacionais (Convenção sobre o combate da corrupção de funcionários públicos estrangeiros em transações comerciais).

O Conselho Nacional de Justiça ${ }^{8}$ revelou que, em 2010, havia em tramitação na Justiça Federal n. 4.261 .535 processos em $1^{\circ}$ grau de jurisdição, dos quais 274.341 eram criminais, ou seja, uma proporção de $93,56 \%$ de processos não criminais contra $6,43 \%$ criminais. O estudo aprofundou a problemática, divulgando que do total das sentenças prolatadas 46,79\% tiveram recursos (tanto da acusação como pela defesa) e $53,21 \%$ não.

Numa realidade distinta, a Justiça Estadual, por meio de sua competência residual, apresentou um total de 33.012.327 processos em trâmite em $1^{\circ}$ grau de jurisdição, dos quais 6.961 .945 eram criminais, representando a proporção de $78,91 \%$ não criminais contra $21,08 \%$ criminais. O mais assustador é que $80,37 \%$ dos casos não tiveram recursos criminais.

Por meio desse estudo, há duas conclusões plausíveis: a primeira é que a criminalidade comum, processada no âmbito estadual, representa mais de $96 \%$ dos processos penais em tramitação no país. Esse dado demonstra a seletividade garantista do ordenamento constitucional, com viés nitidamente político na manutenção do status quo da ideologia da classe dominante, sinalizando que o acesso à justiça possui "entradas" distintas para ricos e pobres. O acesso à justiça penal em âmbito federal é mais seletivo, mais caro para o Estado e menos produtivo, não obstante, as regras processuais, em geral, são aplicadas aos processos criminais da justiça estadual (REIS, 2012, p. 8).

Diga-se isso porque a criminalização primária produz tipos penais selecionados que vão interferir à sua medida nos interesses da União Federal, que em última análise é uma abstração jurídica. Sob o ponto de vista econômico, social e cultural, os destinatários da Justiça Federal e Estadual possuem o perfil distinto.

Os delitos mais comuns no âmbito federal são apropriação indébita previdenciária, crimes contra a ordem tributária, lavagem de dinheiro,

${ }^{8}$ Disponível em: <http://www.cnj.jus.br/images/programas/justicaemnumeros/2010/rel_ justica_numeros_2010.pdf $>$. Acesso em: 9 jul. 2014. 
contrabando e descaminho. Veja que são crimes cometidos por intermédio de pessoa jurídica, sob a responsabilidade do empresário ou empregado responsável do alto escalão.

A segunda conclusão corrobora todo o argumento descrito: aqueles que possuem maiores recursos econômico-financeiros, maiores possibilidades de entender o caráter ilícito de sua conduta e de apresentar soluções ou alternativas de entendimento, ou mesmo alcance sobre o tipo penal imputado, conseguem resistir de maneira mais efetiva à pretensão punitiva do Estado e, portanto, ampliam a chance de absolvição. Conseguir tempo, produzir provas, acessar e acompanhar o processo são detalhes imprescindíveis na defesa penal; porém, isso exige combatividade e resistência, o que não se verifica no âmbito estadual, local onde se apura maior quantidade de crimes de indivíduos vulneráveis juridicamente.

\section{Conclusão}

O crime é uma construção de ordem política, pois o que define uma ação como criminal é um conjunto de dispositivos eminentemente políticos: pacto, constituição, código penal, código de processo penal, aparato policial, administração pública da segurança, poder judiciário, penitenciárias.

A ordem formal, responsável pela criação e limitação das condutas penais, é oriunda de uma ideologia dominante, a qual percebe a criminalidade como um problema externo (do outro, outsiders), a manter com ela uma relação de exterioridade e, portanto, com viés de imunizar estratos sociais do alto escalão. Isso significa que a impunidade e a criminalização (e também a vitimação) são orientadas pela seleção desigual de pessoas, de acordo com uma fortíssima estereotipia presente no senso comum e nos agentes do controle penal, e não pela incriminação igualitária de condutas, como programa o discurso jurídico-penal.

A justiça penal brasileira revela uma grande parcela homogênea de criminosos etiquetada pela classe social que ocupa, pela posição dentro da comunidade, raça e outros fatores que só demonstram o quanto a ideologia da defesa social e de um bem comum a todos é falaciosa. 
Há uma clara demonstração de que nem todos são igualmente vulneráveis ao sistema penal, que costuma se orientar por estereótipos que recolhem os caracteres dos setores marginalizados; os economicamente poderosos (powerfull) e com condições financeiras para patrocinar uma defesa técnica especializada e competente possuem maior chance de resistir às persecuções criminais.

Além dessa predominante formação de leis que atingem as classes mais baixas, percebe-se também uma seleção criminalizadora por meio de formulação técnica dos tipos penais e a espécie de conexão que eles determinam com o mecanismo das agravantes e atenuantes. Somente alguns possuem a seu favor recursos e "remédios constitucionais" como forma de não sofrer determinada pena.

Respondendo à provocação central do tema proposto, pode-se dizer que o discurso garantista se aplica a uma pequena parcela dos criminosos, que possui condições para transportar as garantias teórico-abstratas para o plano prático-reformista.

\section{Referências}

ANDRADE, Vera Regina Pereira de. Pelas mãos da criminologia: o controle penal para além da (des)ilusão. Rio de Janeiro: Revan, 2012.

. A ilusão de segurança jurídica: do controle da violência à violência do controle penal. Porto Alegre: Livraria do Advogado Editora, 2003.

ANDRADE, Manuel da Costa.; DIAS, Jorge de Figueiredo.

Criminologia: o homem delinquente e a sociedade criminógena. 2. reimp. Coimbra: Coimbra, 1997.

BARATTA, Alessandro. Criminologia crítica e crítica ao direito penal, 3. ed. Rio de Janeiro: Revan, 2002.

BECKER, Howard Saul. Outsiders: estudos de sociologia do desvio. Rio de janeiro: Zahar, 2008. 
BRAGA, Ana Gabriela Mendes. Preso pelo Estado e vigiado pelo crime: as leis do cárcere e a construção da identidade na prisão. Rio de janeiro: Lumen Juris, 2013.

BIZZOTTO, Alexandre. A inversão ideológica do discurso garantista: a subversão da finalidade das normas constitucionais de conteúdo limitativo para ampliação do sistema penal. Rio de Janeiro: Editora Lumen Juris, 2009.

CHOUKR, Fauzi Hassan. Processo penal de emergência. Rio de Janeiro: Editora Lumen Juris, 2002.

CUNHA, Rosa Maria Cardoso da. O caráter retórico do princípio da legalidade. Porto Alegre: Síntese, 1979.

DULTRA, Rogério. Pesquisa inédita revela que Brasil prende em excesso. Entrevista ao Projeto Pensando o Direito, 5 maio 2015. Disponível em: <http://pensando.mj.gov.br/2015/05/05/pesquisa-ineditarevela-que-brasil-prende-em-excesso/ > . Acesso em: 7 maio 2015.

ELBERT, Carlos Alberto. Novo manual básico de criminologia. Porto Alegre: Livraria do Advogado Editora, 2009. p.155-176.

FERRACUTI, Franco. Aspetti criminologici dele frode alimentari. Roma: Recerche, 1970.

FERRAJOLI, Luigi. Direito e razão: teoria do garantismo penal. Trad. de Ana Paula Zomer et al. São Paulo: RT, 2002.

. La desigualdade ante la justicia penal y la garantia de la defensa pública. Defensa pública: garantia de acesso a la justicia. Ministerio Público de la Defensa Argentina. Buenos Aires: La Ley, 2008. FERREIRA JUNIOR, Hédio. Entrevista com Antonio Carlos de Almeida Castro. [2014]. Disponível em: <http:/www.univem.edu.br/ noticias/?id=1867>. Acesso em: 9 jul. 2014.

FOUCAULT, Michel. Vigiar e punir: história da violência nas prisões. Trad. Ligia M. Pondé Vassalo. Petrópolis: Vozes, 1987.

. Em defesa da sociedade. Trad. Maria Hermantina Galvão. São Paulo: Martins Fontes, 1999. 
GARLAND, David. A cultura do controle: crime e ordem social na sociedade contemporânea. Pensamento criminológico, v. 16. Rio de Janeiro: Revan, 2008.

MASCARO, Alysson Leandro. Filosofia do direito, 4. ed. São Paulo: Atlas, 2014.

MASSUD, Leonardo. $O$ crime de colarinho branco numa perspectiva criminológica. 21 set 2012. Disponível em: <http://www.massudsarcedo.adv.br/site/artigos.php?id=35>. Acesso em: 22 jun. 2014.

MISSE, Michel. Crime e violência no Brasil Contemporâneo: estudos de sociologia do crime e da violência urbana. 2. tiragem. Rio de Janeiro: Editora Lumen juris, 2011.

REIS, Fernando Antônio Calmon. Acesso à justiça: desigualdade e garantismo. Disponível em <http://www.criminologiacritica.com.br/ arquivos/1368110753.pdf>. Acesso em: 9 jul. 2014.

SANTOS, Cláudia Cruz. O crime de colarinho branco, a (des)igualdade e o problema dos modelos de controlo. In: PODVAL, Roberto (Org.).

Temas de Direito Penal Econômico. São Paulo: RT, 2001. p. 192-222.

SANTOS, Inês Moreira. Crime de colarinho branco: práticas inconfessáveis. In: COSTA, José Faria; SILVA, Marco Antonio Marques (Coord.). Direito Penal Especial, Processo Penal e Direitos Fundamentais: Visão Luso-Brasileira. São Paulo: Quartier Latin, 2006. p. 1.152-1.171.

THOMPSON, Augusto. Quem são os criminosos? 2. ed. Rio de Janeiro: Editora Lumen juris, 2007.

Marisa Helena D'Arbo Alves de Freitas é professora da Faculdade de Ciências Humanas e Sociais da Universidade Estadual Paulista Júlio de Mesquita Filho (UNESP - Campus de Franca) e da Universidade Paulista (UNIP - Campus de Ribeirão Preto), membro do Núcleo de Estudos da Tutela Penal e Educação em Direitos Humanos (NETPDH) e Doutora em Direito pela UNESP. 
E-mail: madarbo@uol.com.br.

Endereço profissional: Universidade Estadual Paulista Júlio de Mesquita Filho, Avenida Eufrásia Monteiro Petraglia, n. 900, Jd. Antonio Petraglia, Franca, SP 14409-160, Caixa Postal 211.

Renan Posella Mandarino é mestre em Direito pela Faculdade de Ciências Humanas e Sociais da Universidade Estadual Paulista Júlio de Mesquita Filho (UNESP) e pós-graduado em Direito Penal e Processual Penal pela Fundação Armando Alvares Penteado (FAAP).

E-mail: remandarino@yahoo.com.br.

Endereço profissional: UNESP, Avenida Eufrásia Monteiro Petraglia, n. 900, Jd. Antonio Petraglia, 14409-160, Franca, SP - Brasil - Caixa Postal 211.

Larissa Rosa é mestre em Direito pela Faculdade de Ciências Humanas e Sociais da Universidade Estadual Paulista Júlio de Mesquita Filho (UNESP) e pósgraduada em Direito Constitucional pela Universidade Anhanguera (UNIDERP). E-mail: Larissa_51@hotmail.com.

Endereço profissional: UNESP, Avenida Eufrásia Monteiro Petraglia, n. 900, Jd. Antonio Petraglia, 14409-160, Franca, SP - Brasil - Caixa Postal 211. 
